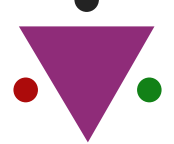

IJCRR

Section: Healthcare

Sci. Journal Impact

Factor: $6.1(2018)$

ICV: 90.90 (2018)

(c) (1) (3)

Copyright@IJCRR

\title{
Overexpression of HNRNPA2B1 is Associated with Poor Prognosis in Head and Neck Squamous Cell Carcinoma
}

\author{
Aswani E' ${ }^{1}$, Gheena $\mathbf{S}^{1}$, Pratibha $\mathbf{R}^{1}$, Abilasha $\mathbf{R}^{1}$, Hannah $\mathbf{R}^{1}$, Paramasivam $\mathbf{A}^{2}$ \\ 'Department of oral pathology, Saveetha Dental College and Hospitals,Saveetha Institute of Medical and Technical Sciences, Saveetha Univer- \\ sity, Chennai, Tamilnadu - 600077, India; ' ${ }^{2}$ epartment of Dental Research Cell,Saveetha Dental College and Hospitals,Saveetha Institute of \\ Medical and Technical Sciences, Saveetha University, Chennai, Tamilnadu - 600077, India.
}

\section{ABSTRACT}

Introduction: Head and neck squamous cell carcinoma (HNSCC) is an aggressive life-threatening disease associated with high mortality rates. Heterogeneous nuclear ribonucleoprotein A2B1 (HNRNPA2B1) is tightly linked to tumorigenesis. Recent studies have shown that HNRNPA2B1 is a mediator of N6-methyladenosine (m6A)-dependent nuclear RNA processing events. However, the role of HNRNPA2B1 in head and neck squamous cell carcinoma (HNSCC) is largely unknown.

Objective: To check the expression profile for HNRNPA2B1 in HNSCC using the Oncomine datasets and TIMER database.

Methods: Therefore, in the present study, we used the large TCGA RNA sequencing (RNAseq) dataset to explore the HNRNPA2B1 expression level in HNSCC. We also used Kaplan-Meier plotter to evaluate the effect of HNRNPA2B1 on clinical prognosis.

Results: HNRNPA2B1 was significantly upregulated in HNSCC compared to normal tissues $(p<0.05)$. Moreover, the increased expression of HNRNPA2B1 mRNA was closely associated with reduced overall survival (OS) $(p=0.0099)$ in HNSCC patients.

Conclusion: Our findings systematically elucidate the expression profiles and instinct prognostic value of HNRNPA2B1 in HNSCC, which might provide a novel therapeutic target and potential prognostic biomarker for HNSCC patients.

Key Words: HNRNPA2B1, HNSCC, Prognostic value, m6A, m6A regulator, TCGA database

\section{INTRODUCTION}

Head and neck squamous cell carcinoma (HNSCC) is aggressive and it is an epithelial-derived from mucosal linings of the oral cavity, oropharynx, larynx, or hypopharynx..,2 According to the recently published report GLOBOCAN 2018 (global cancer statistics) more than 8 lakhs new HNSCC cases are diagnosed every year., ${ }^{1,3}$ Main etiological factor for HNSCC is alcohol, tobacco, and HPV infection. ${ }^{4,5,6}$ Therefore, the treated patients often have a recurrence experience of $40-60 \%$ and are unresponsive to subsequent therapeutic interventions. ${ }^{7,5,8}$ Therefore, despite the improvement in overall survival (OS) for patients with other tumor types, the 5 year OS rate of HNSCC has not changed much over the past decade. ${ }^{1,9}$ Despite numerous advances in therapeutic methods, the prognosis of HNSCC patients still remains poor. Therefore, there was an ultimate and an urgent need to have a better understanding of the molecular mechanism underlying $\mathrm{HNSCC}$ population progression and to identify essential genes that could serve as effective biomarkers and potential treatment targets. ${ }^{10,11}$

Heterogeneous nuclear ribonucleoproteins(H2/B1)is a protein-coding gene that has abundant RNA binding proteins expressed in most human tissues. ${ }^{12}$ Increasing evidence suggests that some HNRNPA2B1 play a direct role in tumor development and progression. ${ }^{13,14}$

Previous research showed overexpression of HNRNPA2B1 in lungs, ${ }^{15,16}$ breast cancers ${ }^{17}$, and liver cancers. ${ }^{18}$ Furthermore, knockdown of this gene in breast cancer cells induced apoptosis and HNRNPA2B1 plays an important role as a driver oncogene in glioblastoma development and acts as a predictor of glioblastoma patient survival. ${ }^{17}$ Recent studies have found that HNRNPA2B1 modulates hypoxia via alternative splicing glycolytic pyruvate kinase isozyme 2 (PKM2) enzyme in cancer cells. ${ }^{19}$ However, some reports had pointed

\section{Corresponding Author:}

Paramasivam A, Department of Dental Research Cell, Saveetha Dental College \& Hospital, Saveetha Institute of Medical and Technical Sciences [SIMATS], Saveetha University, Poonamallee High Road, Chennai, Tamilnadu - 600077, India; Phone: 8790250246; E-mail: paramasivama.sdc@saveetha.com

ISSN: 2231-2196 (Print)

Received: 14.08 .2020
ISSN: 0975-5241 (Online)

Revised: 10.09 .2020
Accepted: 12.10 .2020

Published: 26.12 .2020 
out that HNRNPA2B1 could promote tumorigenesis. The role of HNRNPA2B1 in HNSCC remains largely unknown.

\section{MATERIALS AND METHODS}

\section{Gene expression analysis}

In the current study, ONCOMINE, ${ }^{20}$ Tumor Immune Estimation Resource (TIMER $)^{21}$ and UALCAN ${ }^{21}$ databases were applied to analyze the $H N R N P A 2 B 1$ expression in primary HNSCC and normal tissues.

\section{Survival analysis by Kaplan-Meier plotter}

In the present study, the prognostic values of HNRNPA2BI at mRNA level in HNSCC was analyzed using Kaplan-Meier Plotter (http://kmplot.com/analysis/) is an online database containing gene expression profiles and survival information of cancer patients. ${ }^{22}$

\section{Statistical analysis}

It was performed on the bioinformatics database online or using SPSS 21.0 software. The differential mRNA expression of HNRNPA2B1 gene for HNSCC was analyzed by student t-test. Kaplan- Meier plots were generated with course, bye-bye lock-rank tests. For all analyses, differences considered statistically significant P-values are less than 0.05 .

\section{RESULTS}

\section{Overexpression of HNRNPA2B1 in various type of cancer}

We first used Oncomine and TIMER databases to analyze the transcriptional level of HNRNPA2B1 in various types of cancers and corresponding normal tissues. The results showed that HNRNPA2B1 increased in most types of cancers, including HNSCC, breast, brain, bladder, cervical, colorectal cancers (Figure 1A, 1B).

\section{Overexpression of HNRNPA2B1 correlated with poor survival in HNSCC}

We also used UALCAN database to analyze the mRNA level of HNRNPA2B1 in HNSCC and corresponding normal tissues. Box plot showed that HNRNPA2B1 mRNA levels were significantly higher in HNSCC compared with control tissues $(\mathrm{P}=1.624 \mathrm{e}-12$, Figure $2 \mathrm{~A})$. By using the $\mathrm{KM}$ plotter, we found that high HNRNPA2B1 expression was associated with poor overall survival $(\mathrm{P}=0.0099$, Figure $2 \mathrm{~B})$.

\section{DISCUSSION}

HNSCC is the sixth leading cancer by incidence worldwide and cancers of the oral cavity, and oropharynx is the most common HNSCC. Tobacco chewing is a major cause of oral and oropharyngeal cancers. ${ }^{1,2,23}$ The $h n R N P A / B$ protein families are overexposed or downregulated in various cancers and likely account for the oncogenic effects of several types of cancer. ${ }^{17,24}$ Recent studies have shown that HNRNPA2BI plays a critical role in carcinogenesis and the progression of cancer ${ }^{25,26,27}$ Increased expression of HNRNPA2B1 protein was observed in pancreatic cancer, lung cancer and may act as a biomarker for early detection. ${ }^{15,28}$ Moreover, overexpression of HNRNPA2B1 was reported in glioblastoma(10), breast cancer, ${ }^{17}$ hepatocellular carcinoma ${ }^{29}$ and neurodegenerative. ${ }^{30}$ Studies regarding the HNRNPA2B1 gene in $\mathrm{HN}$ $\mathrm{SCC}$ is minimal and largely unknown. Even the prognosis of HNSCC is also poor. Therefore, it is an urgent need to have a better understanding of the molecular mechanism underneath the HNSCC progression and to identify the essential genes that could serve as effective biomarkers and potential treatment targets.

Therefore, in the present study, the expression profile for HNRNPA2B1 in HNSCC was first determined using the Oncomine datasets and TIMER database. We demonstrated that HNRNPA2B1 was highly expressed in various types of cancer including HNSCC. Recent studies reported that high expression of HNRNPA2B1 was correlated with poor prognosis. In this study, we employed Kaplan-Meier plotter to evaluate the prognostic value of HNRNPA2B1 in HNSCC patients and the result showed a high expression of $H N R N P A 2 B 1$ was significantly associated with poor overall survival (OS) of HNSCC patients. Overexpression of HNRNPA2B1 gene in HNSCC, which is similar to the overexpression in breast cancer, ${ }^{17,31,32}$ glioblastoma, ${ }^{10,33}$ neurodegeneration, ${ }^{30}$ lung cancer $^{34}$, and pancreatic cancer (27).

\section{CONCLUSION}

HNRNPA2B1 mRNA expression level was increased in $\mathrm{HN}$ SCC. In addition, HNRNPA2B1 increased expression was significantly related to poor survival in HNSCC patients. These findings suggest that HNRNPA2B1 may be used as a prognostic biomarker for HNSCC. The results may be validated and analyzed using in vitro and in vivo studies.

\section{Acknowledgment: None}

\section{Conflict of interest: None}

Financial support: None

\section{REFERENCES}

1. Bray F, Ferlay J, Soerjomataram I, Siegel RL, Torre LA, Jemal A. Global cancer statistics 2018: GLOBOCAN estimates of incidence and mortality worldwide for 36 cancers in 185 coun- 
tries. CA Cancer J Clin 2018;68(6):394-424.

2. Thangaraj SV, Shyamsundar V, Krishnamurthy A, Ramani P, Ganesan K, Muthuswami M, et al. Molecular Portrait of Oral Tongue Squamous Cell Carcinoma Shown by Integrative MetaAnalysis of Expression Profiles with Validations. PLoS One 2016;11(6):e0156582.

3. Jayaraj G, Sherlin HJ, Ramani P, Premkumar P, Natesan A. Stromal myofibroblasts in oral squamous cell carcinoma and potentially malignant disorders. Indian J Cancer 2015; 52(1):87.

4. Canning M, Guo G, Yu M, Myint C, Groves MW, Byrd JK, et al. Heterogeneity of the Head and Neck Squamous Cell Carcinoma Immune Landscape and Its Impact on Immunotherapy. Front Cell Dev Biol 2019;7:52.

5. Gupta V, Ramani P. Histologic and immunohistochemical evaluation of mirror image biopsies in oral squamous cell carcinoma. J Oral Biol Craniofac Res 2016;6(3):194-197.

6. Viveka TS, Shyamsundar V, Krishnamurthy A, Ramani P, Ramshankar V. p53 Expression Helps Identify High Risk Oral Tongue Premalignant Lesions and Correlates with Patterns of Invasive Tumor Front and Tumor Depth in Oral Tongue Squamous Cell Carcinoma Cases. Asian Pac J Cancer Prev 2016;17:189-95.

7. Tolstonog G, Simon C. Trends in Surgical Research in Head and Neck Cancer. Curr Treat Options Oncol 2017;18(6):38.

8. Shree KH, Ramani P, Sherlin H, Sukumaran G, Jeyaraj G, Don $\mathrm{KR}$, et al. Saliva as a diagnostic tool in oral squamous cell carcinoma--a systematic review with Meta analysis. Pathol Oncol Res 2019;25(2):447-53.

9. Jemal A, Bray F, Center MM, Ferlay J, Ward E, Forman D. Global cancer statistics. CA Cancer J Clin 2011;61(2):69-90.

10. Deng J, Chen S, Wang F, Zhao H, Xie Z, Xu Z, et al. Effects of hnRNP A2/B1 Knockdown on Inhibition of Glioblastoma Cell Invasion, Growth and Survival. Mol Neurobiol 2016;53(2):113244.

11. Jayaraj G, Sherlin HJ, Ramani P, Premkumar P, Anuja N. Cytomegalovirus and Mucoepidermoid carcinoma: A possible causal relationship? A pilot study. J Oral Maxillofac Pathol 2015;19(3):319.

12. Leemans CR, Snijders PJF, Brakenhoff RH. The molecular landscape of head and neck cancer. Nat Rev Cancer 2018;18(5):26982.

13. Carpenter B, MacKay C, Alnabulsi A, MacKay M, Telfer C, Melvin WT, et al. The roles of heterogeneous nuclear ribonucleoproteins in tumor development and progression. Biochim Biophys Acta 2006;1765(2):85-100.

14. Jayaraj G, Ramani P, Sherlin HJ, Premkumar P, Anuja N. Inter-observer agreement in grading oral epithelial dysplasia-a systematic review. J Oral Maxillofac Surg Med Pathol 2015;27(1):112-6.

15. Fielding P, Turnbull L, Prime W, Walshaw M, Field JK. Heterogeneous nuclear ribonucleoprotein A2/B1 up-regulation in bronchial lavage specimens: a clinical marker of early lung cancer detection. Clin Cancer Res 1999;5(12):4048-52.

16. Zhou J, Allred DC, Avis I, Martínez A, Vos MD, Smith L, et al. Differential Expression of the Early Lung Cancer Detection Marker, Heterogeneous Nuclear Ribonucleoprotein-A2/B1 (hnRNP-A2/B1) in Normal Breast and Neoplastic Breast Cancer. Breast Cancer Res Treat 2001;66(3):217-24.

17. Hu Y, Sun Z, Deng J, Hu B, Yan W, Wei H, et al. Splicing factor hnRNPA2B1 contributes to tumorigenic potential of breast cancer cells through STAT3 and ERK1/2 signaling pathway. Tumor Biology 2017;39(3):1010428317694318.

18. Chen M, Wong C-M. The emerging roles of N6-methyladenosine (m6A) deregulation in liver carcinogenesis. Mol Cancer 2020;19(1):44.
19. Clower CV, Chatterjee D, Wang Z, Cantley LC, Vander Heiden MG, Krainer AR. The alternative splicing repressors hnRNP A1/ $\mathrm{A} 2$ and PTB influence pyruvate kinase isoform expression and cell metabolism. Proc Natl Acad Sci USA 2010;107(5):1894-9.

20. Rhodes DR, Kalyana-Sundaram S, Mahavisno V, Varambally R, Yu J, Briggs BB, et al. Oncomine 3.0: Genes, Pathways, and Networks in a Collection of 18,000 Cancer Gene Expression Profiles. Neoplasia 2007;9:166-80.

21. Li T, Fu J, Zeng Z, Cohen D, Li J, Chen Q, et al. TIMER2.0 for analysis of tumor-infiltrating immune cells [Internet]. Nucleic Acids Res 2020;48(W1):W509-W514.

22. Nagy Á, Lánczky A, Menyhárt O, Győrffy B. Validation of miRNA prognostic power in hepatocellular carcinoma using expression data of independent datasets. Sci Rep 2018;8(1):9227.

23. Shindhe VM, Shindhe MM, Kulkarni NS, Mehvish M, Javali SB, Balikai FB, Jaalam K. A Study on Effect of Smokeless Tobacco on Pulmonary Function Tests in Class IV Workers of USM-KLE (UniversitiSains Malaysia-Karnataka Lingayat Education Society) International Medical Programme, Belagavi. Int J Cur Res Rev 2020;12 (18):1-19.

24. Sridharan G, Ramani P, Patankar S. Serum metabolomics in oral leukoplakia and oral squamous cell carcinoma. J Cancer Res Ther 2017;13(3):556-61.

25. Gheena S, Ezhilarasan D. Syringic acid triggers reactive oxygen species-mediated cytotoxicity in HepG2 cells. Hum Exp Toxicol 2019;38(6):694-702.

26. Sherlin H, Ramani P, Premkumar P, Kumar A, Natesan A. Expression of CD 68, CD 45 and human leukocyte antigen-DR in central and peripheral giant cell granuloma, giant cell tumor of long bones, and tuberculous granuloma: An immunohistochemical study. Indian J Dent Res 2015;26(3):295-303.

27. Hannah R, Ramani P, Sherlin HJ, Ranjith G, Ramasubramanian A, Jayaraj G, et al. Awareness about the use, ethics and scope of dental photography among undergraduate dental students dentist behind the lens. Res J Pharma Tech 2018;11(3):1012-6.

28. Yan-Sanders Y, Hammons GJ, Lyn-Cook BD. Increased expression of heterogeneous nuclear ribonucleoprotein A2/B1 (hnRNP) in pancreatic tissue from smokers and pancreatic tumor cells. Cancer Lett 2002 Sep 26;183(2):215-20.

29. Mizuno H, Honda M, Shirasaki T, Yamashita T, Yamashita T, Mizukoshi E, et al. Heterogeneous nuclear ribonucleoprotein A2/B1 in association with hTERT is a potential biomarker for hepatocellular carcinoma. Liver Int 2012;32(7):1146-55.

30. Martinez FJ, Pratt GA, Van Nostrand EL, Batra R, Huelga SC, Kapeli K, et al. Protein-RNA Networks Regulated by Normal and ALS-Associated Mutant HNRNPA2B1 in the Nervous System. Neuron 2016;92(4):780-95.

31. Sivaramakrishnan SM, Ramani P. Study on the Prevalence of Eruption Status of Third Molars in South Indian Population. Early Pregnancy 2015;7(4):1.

32. Swathy S, Gheena S, Varsha SL. Prevalence of pulp stones in patients with history of cardiac diseases. Res J Pharma Tech 2015;8(12):1625-8.

33. Jangid K, Alexander AJ, Jayakumar ND, Varghese S, Ramani P. Ankyloglossia with cleft lip: A rare case report. J Indian Soc Periodontol 2015;19(6):690-3.

34. Tockman MS, Mulshine JL, Piantadosi S, Erozan YS, Gupta PK, Ruckdeschel JC, et al. Prospective detection of preclinical lung cancer: results from two studies of heterogeneous nuclear ribonucleoprotein A2/B1 overexpression. Clin Cancer Res 1997;3(12 Pt 1):2237-46. 

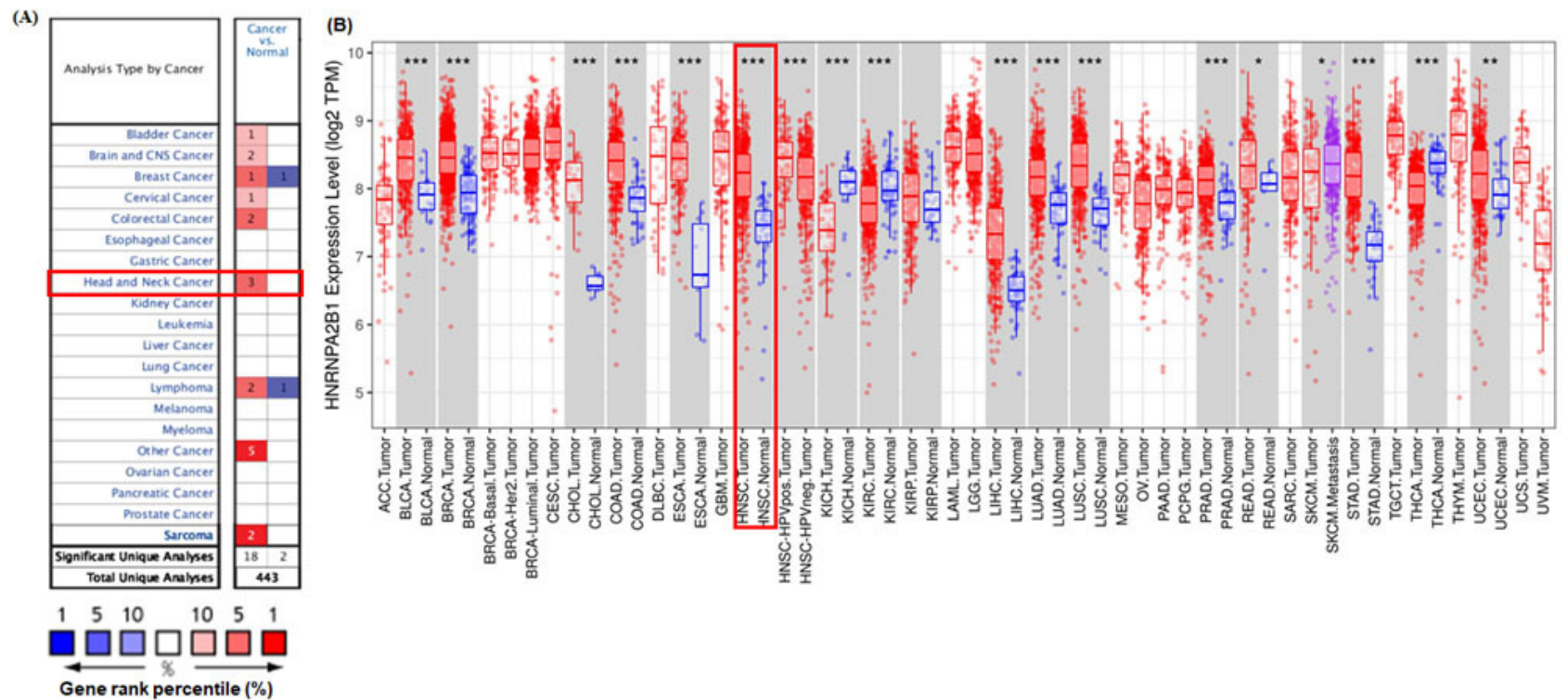

Figure 1: HNRNPA2B1expression levels in human cancers: $(A)$ HNRNPA2B1 in data sets of different cancers in the Oncomine database (red, overexpression; blue, downexpression). (B) HNRNPA2B1 expression levels in different tumor types from TCGA database were determined by TIMER $\left({ }^{*} \mathrm{P}<0.05,{ }^{* *} \mathrm{P}<0.01,{ }^{* * *} \mathrm{P}<0.001\right)$.

(A)

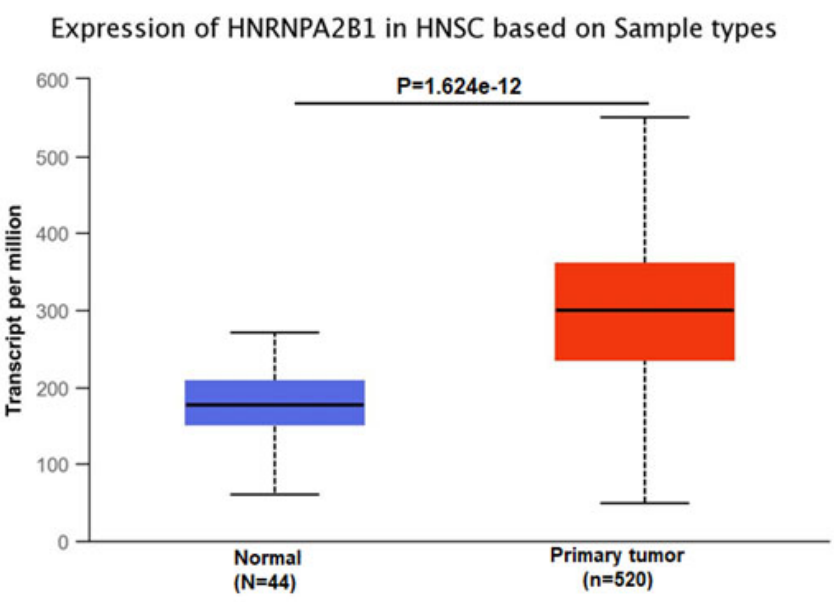

(B)

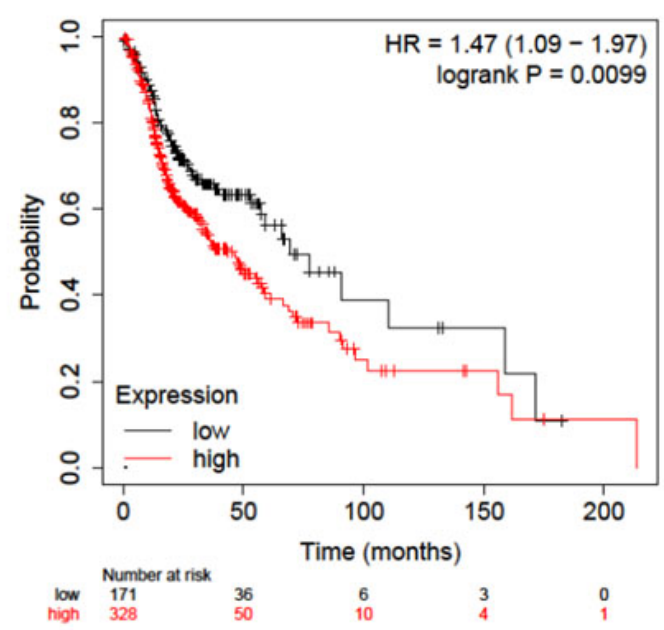

Figure 2: (A) Boxplot showing HNRNPA2B1 expression in patients with HNSCC and normal tissues (P=1.624e-12). (B) KaplanMeier curves indicated HNSCC patients had poorer survival in high expression of HNRNPA2B1 $(\mathrm{P}=0.0099)$. 